\title{
Karyotype diversity and chromosomal organization of repetitive DNA in Tityus obscurus (Scorpiones, Buthidae)
}

Bruno Rafael Ribeiro de Almeida', Susana Suely Rodrigues Milhomem-Paixão², Renata Coelho Rodrigues Noronha', Cleusa Yoshiko Nagamachi', Marlyson Jeremias Rodrigues da Costa ${ }^{1}$, Pedro Pereira de Oliveira Pardal ${ }^{3}$, Johne Souza Coelho ${ }^{3}$ and Julio Cesar Pieczarka ${ }^{1 *}$

\begin{abstract}
Background: Holocentric chromosomes occur in approximately 750 species of eukaryotes. Among them, the genus Tityus (Scorpiones, Buthidae) has a labile karyotype that shows complex multivalent associations during male meiosis. Thus, taking advantage of the excellent model provided by the Buthidae scorpions, here we analyzed the chromosomal distribution of several repetitive DNA classes on the holocentric chromosomes of different populations of the species Tityus obscurus Gervais, 1843, highlighting their involvement in the karyotypic differences found among them.

Results: This species shows inter- and intrapopulational karyotype variation, with seven distinct cytotypes: A $(2 n=16), B(2 n=14), C(2 n=13), D(2 n=13), E(2 n=12), F(2 n=12)$ and $G(2 n=11)$. Furthermore, exhibits achiasmatic male meiosis and lacks heteromorphic sex chromosomes. Trivalent and quadrivalent meiotic associations were found in some cytotypes. In them, $45 \mathrm{~S}$ rDNAs were found in the terminal portions of two pairs, while TTAGG repeats were found only at the end of the chromosomes. In the cytotype $A(2 n=16)$, the U2 snRNA gene mapped to pair 1, while the $\mathrm{H} 3$ histone cluster and $\mathrm{C}_{0} \mathrm{t}-1 \mathrm{DNA}$ fraction was terminally distributed on all pairs. Mariner transposons were found throughout the chromosomes, with the exception of one individual of cytotype A $(2 n=16)$, in which it was concentrated in heterochromatic regions.

Conclusions: Chromosomal variability found in T. obscurus are due to rearrangements of the type fusion/fission and reciprocal translocations in heterozygous. These karyotype differences follow a geographical pattern and may be contributing to reproductive isolation between populations analyzed. Our results also demonstrate high mobility of histone $\mathrm{H} 3$ genes. In contrast, other multigene families (45S rDNA and U2 snRNA) have conserved distribution among individuals. The accumulation of repetitive sequences in distal regions of $T$. obscurus chromosomes, suggests that end of chromosome are not covered by the kinetochore.
\end{abstract}

Keywords: Holocentric chromosomes, Repetitive DNA, Multivalent association, Scorpiones, Tityus

\footnotetext{
* Correspondence: juliopieczarka@gmail.com

${ }^{1}$ Laboratório de Citogenética, Centro de Estudos Avançados da

Biodiversidade, Instituto de Ciências Biológicas, Universidade Federal do Pará,

Avenida Augusto Corrêa, n01, Av. Perimetral, s/n. Guamá, 66075-900 Belém,

Pará, Brazil

Full list of author information is available at the end of the article
}

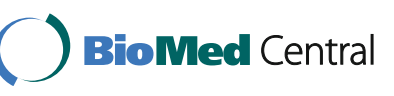

(c) The Author(s). 2017 Open Access This article is distributed under the terms of the Creative Commons Attribution 4.0 International License (http://creativecommons.org/licenses/by/4.0/), which permits unrestricted use, distribution, and reproduction in any medium, provided you give appropriate credit to the original author(s) and the source, provide a link to the Creative Commons license, and indicate if changes were made. The Creative Commons Public Domain Dedication waiver (http://creativecommons.org/publicdomain/zero/1.0/) applies to the data made available in this article, unless otherwise stated. 


\section{Background}

Holocentric chromosomes, which occur in approximately 750 species of eukaryotes, are characterized by the presence of a diffuse centromere wherein the kinetochore proteins are located along the chromatids [1]. The holocentric condition appears to favor the emergence of extensive intra- and interspecific karyotype variability mainly generated by chromosomal fusions or fissions [2, 3]. This feature has emerged independently during evolution, especially among plants, nematodes and arthropods [4]. In Arachnida, holocentric chromosomes are found in the Aranae, Acari and Scorpiones. Within the latter order, they have been reported only in the Buthidae [5].

Buthidae scorpions offer an excellent model for studying the dynamics of holocentric chromosomes, since the diploid number is highly conserved in some genera but highly variable in others [6]. Moreover, some members show complex multivalent pairing during male meiosis [7], reflecting the gradual accumulation of multiple fusions/fissions and/or translocations [8]. Depending on the degree of structural heterozygosity, the chains or rings may differ in size at the interpopulational, intrapopulation, and/or intraindividual levels [9-11].

In Buthidae, few studies have examined the chromosomal distribution of repetitive DNA, and are restricted to the $45 \mathrm{~S}$ rDNA and telomeric sequences mapping $[11,12]$. In other arthropods with holocentric systems, repetitive sequences have proven useful in the chromosomal mapping-based identification of chromosome pairs [13]. Such sequences also function in homologous meiotic pairing [14], chromosomal segregation during cell division [15], and the stability of chromosomal ends in the absence of telomerase [16]. Thus, additional studies are warranted to improve our understanding of the dynamics of the holocentric chromosomes in Scorpiones.

The genus Tityus (Scorpiones, Buthidae) comprises some 170 species that are exclusively neotropical and occur from the Dominican Republic to Central Argentina [17]. Only $10 \%$ of the species in this genus have been cytogenetically analyzed; they exhibit karyotypes with low diploid numbers $(2 \mathrm{n}=5$ to 27$)$ and no heteromorphic sex chromosomes [18]. Thus, taking advantage of the excellent model provided by the Buthidae scorpions, here we analyzed the chromosomal distribution of several repetitive DNA classes on the holocentric chromosomes of different populations of the species Tityus obscurus Gervais, 1843, highlighting their involvement in the karyotypic differences found among them.

\section{Results}

\section{Karyotype}

The karyotype of $T$. obscurus consists of holocentric chromosomes and lacks heteromorphic sex chromosomes. The diploid number and chromosome size showed inter- and intrapopulation variations, with seven distinct cytotypes.

The cytotype A $(2 n=16)$ comprises twenty one individuals from Belém, Santa Bárbara, Moju, Benevides, Bragança and Acará, with karyotype constituted by two large and fourteen medium chromosomes (Fig. 1a). C-bands were observed on terminal regions of pairs $1,2,3,4$ and 5 , while the pairs 6, 7 and 8 showed no visible C-bands (Fig. 1b).

The cytotype B $(2 n=14)$ comprises one individual male from Santarém and five individuals from Afuá, with karyotype constituted by four large and ten medium chromosome (Fig. 1c). C-bands were observed on terminal regions of pairs 1, 3, 4 5, 6 and 7 while the pair 2 showed no visible C-bands (Fig. 1d).

The cytotype $C(2 n=13)$ comprises one individual male from Afuá, with karyotype constituted by one extremely large, three large and nine medium chromosome (Fig. 1e). The pair 7 showed absence of homologous member. Cbands were observed on terminal regions of pairs 1, 2, 3, 4 and 7, while one interstitial C-band was visualized only on a homologous member of the pair 1 (Fig. 1f).

The cytotype D $(2 n=13)$ comprises one individual male from Santarém, with karyotype constituted by five large and eigth medium chromosome (Fig. 1g). C-bands were observed on terminal regions of pairs 1, 2, 3 and 6 (Fig. 1h).

The cytotype $\mathrm{E}(2 \mathrm{n}=12)$ comprises three individuals from Rurópolis and one individual male from Santarém, with karyotype constituted by six large and six medium chromosome (Fig. 1i). C-bands were observed on terminal regions of all pairs (Fig. 1j).

The cytotype $\mathrm{F}(2 \mathrm{n}=12)$ comprises one individual male from Santarém, with karyotype constituted by one extremely large, five large and six medium chromosome (Fig. 1k). C-bands were observed on terminal regions of pairs 1, 2, 3, 5 and 6 while one interstitial C-band was visualized only on a homologous member of the pair 1 (Fig. 11).

The cytotype $\mathrm{G}(2 \mathrm{n}=11)$ comprises one individual male from Santarém, with karyotype constituted by one extremely large, five large and five medium chromosome (Fig. $1 \mathrm{~m}$ ). C-bands were observed on terminal regions of all pairs, while one interstitial $\mathrm{C}$-band was visualized only on a homologous member of the pair 1 (Fig. 1n).

\section{Meiotic analysis}

In meiotic cells, we did not observe chiasma during the post-pachytene phases. Different meiotic configurations were observed as follows: cytotype $B(2 n=14)$ had seven bivalents (Fig. $2 \mathrm{a}$ ); cytotypes $\mathrm{C}$ and D (both $2 \mathrm{n}=13$ ) had five bivalents and one trivalent (Fig. 2b); cytotype $\mathrm{E}$ $(2 \mathrm{n}=12)$ had six bivalents (Fig. $2 \mathrm{c})$; cytotype $\mathrm{F}(2 \mathrm{n}=12)$ had three bivalents and two trivalents (Fig. 2d); cytotype $\mathrm{G}$ $(2 \mathrm{n}=11)$ had four bivalents and one trivalent (Fig. 2e); most of the individuals of the cytotype A $(2 n=16)$ had eight bivalents (Fig. 2f), while one specimen from Acará 

A \|\|\|\|\|\|\|\|

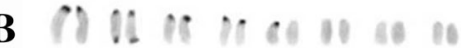
$\begin{array}{llllllll}1 & 2 & 3 & 4 & 5 & 6 & 7 & 8\end{array}$
$\begin{array}{llllllll}1 & 2 & 3 & 4 & 5 & 6 & 7 & 8\end{array}$

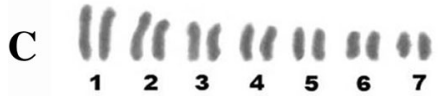

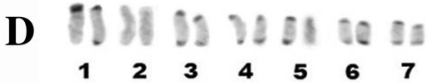

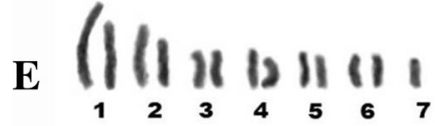

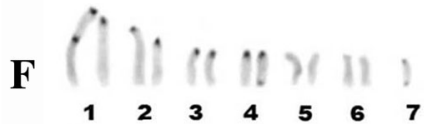
G | $\mid \begin{array}{llllllll}11 & 11 & 11 & 11 & 11 & 1\end{array}$

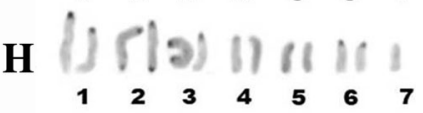
I $(1))(7,1811$
J $60182 \operatorname{sen} 11$

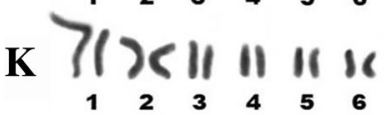
L
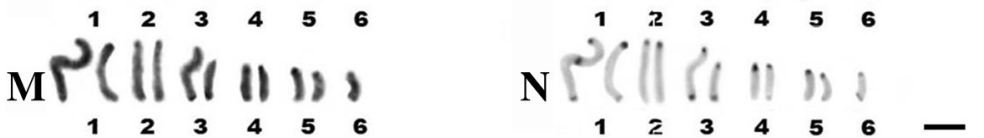

Fig. 1 Karyotypes of Tityus obscurus with giemsa stain $(\mathbf{a}, \mathbf{c}, \mathbf{e}, \mathbf{g}, \mathbf{i}, \mathbf{k})$ and C-banded $(\mathbf{b}, \mathbf{d}, \mathbf{f}, \mathbf{h}, \mathbf{j}, \mathbf{l}, \mathbf{n}):(\mathbf{a}, \mathbf{b})$ cytotype $A, 2 n=16 . \mathbf{c}, \mathbf{d}$ cytotype $B$, $2 n=14$. e, $\mathbf{f}$ cytotype $C, 2 n=13 . \mathbf{g}, \mathbf{h}$ cytotype $D, 2 n=13$. $\mathbf{i}, \mathbf{j}$ cytotype $E, 2 n=12 . \mathbf{k}, \mathbf{I}$ cytotype $F, 2 n=12 . \mathbf{m}, \mathbf{n}$ cytotype $G, 2 n=11$. Barr $=10 \mu m$
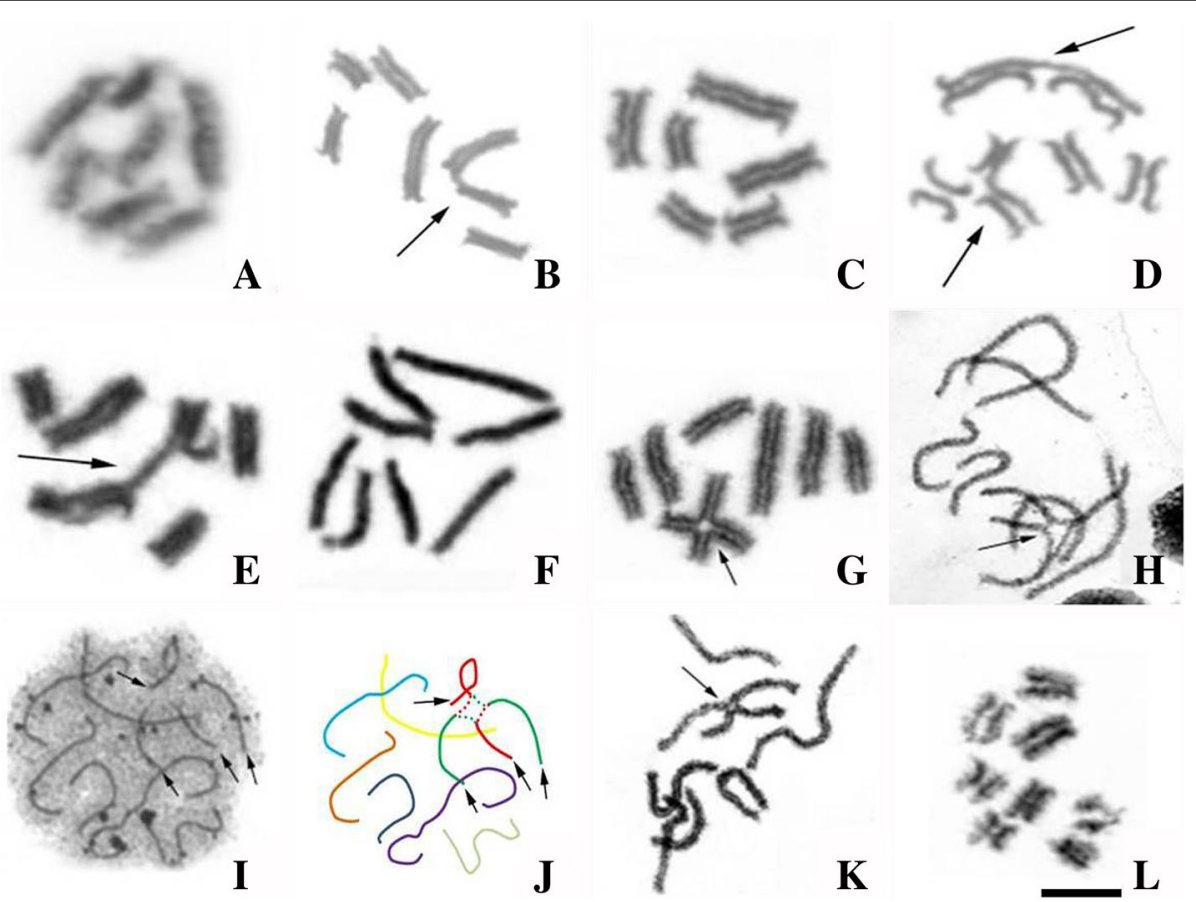

Fig. 2 Meiotic configuration on different specimens of T. obscurus. a Cytotype B, with seven bivalents. b Cytotype C and D, with one trivalent and five bivalents. c Cytotype E, with six bivalents. $\mathbf{d}$ Cytotype F with three bivalents and two trivalent. e Cytotype G with four bivalents and one trivalent. $\mathbf{f}$ Cytotype A with eight bivalents. $\mathbf{g}$ Cytotype A with six bivalents and one quadrivalent. $\mathbf{h}$ Cytotype A with quadrivalent at beginning of pachytene (arrows points the asynaptic region). i Synaptonemal complex analysis in an early pachytene of cytotype A with quadrivalent; the arrow points the asynaptic region of the quadrivalent. $\mathbf{j}$ An schematic interpretation of Fig. 2l. k Cytotype A with quadrivalent at end of pachytene; note the full pairing of the quadrivalente. I Metaphase II, with eight chromosomes. Arrows in (b) (d) and (e) point trivalent associations. Barr $=10 \mu \mathrm{m}$ 
was heterozygous for a reciprocal translocation, and showed six bivalents and one quadrivalent (Fig. 2g).

Conventional staining and synaptonemal complex (SC) analysis in the specimen of the cytotype A $(2 n=16)$ from Acará, which was heterozygous for a reciprocal translocation, demonstrated that the central region of the quadrivalent was non-synaptic in initial and intermediate pachytene cells (Fig. 2h-j). The full pairing happened only at the end of the pachytene phase (Fig. $2 \mathrm{k}$ ). In contrast, the bivalents were completely paired at the initial stage of pachytene (see Fig. 2h). After metaphase II, the cells of the analyzed individual were $n=8$ (Fig. 2l).

\section{Chromosomal mapping of repetitive DNA}

Mapping FISH of the TTAGG repeats was realized in cytotypes $A(2 n=16), E(2 n=12)$ and $F(2 n=12)$ and were restricted to the ends of all chromosomes (Fig. 3a-e). Analysis of the spatial distribution of this sequence in prophasic nuclei showed that the chromosomes were organized in a polarized configuration at the beginning of meiosis I (Fig. 3c).

In the cytotypes A $(2 \mathrm{n}=16), \mathrm{C}(2 \mathrm{n}=13)$ and $\mathrm{F}(2 \mathrm{n}=$ 12) the $45 \mathrm{~S}$ rDNA was found in terminal regions in two pairs (Fig. $3 f-j)$. In the specimen of the cytotype A, heterozygous for a reciprocal translocation, one of the pairs bore this sequence (pair 7) and was part of the quadrivalent observed during meiosis (Fig. 3g).

In the cytotype A $(2 n=16)$, chromosomal mapping of the $C_{0} t-1$ DNA fraction showed that the constitutive heterochromatin regions were rich in highly repetitive DNA sequences (Fig. 4a). In this cytotype, the DAPI+ bands coincided with the heterochromatic block, indicating that the $\mathrm{CH}$ is rich in AT base pairs (Fig. 4b). In contrast, $\mathrm{CMA} 3+$ bands were visualized at the terminal regions of four chromosomes (Fig. 4c). In addition, in the cytotype A, Histone $\mathrm{H} 3$ gene clusters were found in the terminal regions of all chromosomes (Fig. 4d), and the multigene family encoding the U2 snRNA was found on chromosome 1 (Fig. 4e, f).

Regarding the Mariner transposon, the specimen of the cytotype A $(2 \mathrm{n}=16)$, that was heterozygous for a reciprocal translocation, showed a large concentration of this transposon in the $\mathrm{CH}$ regions of some of its bivalents and in the quadrivalent (Fig. 5a-f). Others individuals of the cytotypes A $(2 n=16), C(2 n=13)$ and F $(2 n=$ 12) had small clusters distributed along their chromosomes, either uniformly occupying euchromatic regions or as heterochromatin (Fig. 5g-i).

\section{Discussion}

The role of heterozygous rearrangements in chromosomal evolution of Tityus obscurus

Our date demonstrated than fusions/fissions are involved in the karyotype variability of T. obscurus. Several studies have identified polymorphisms of the diploid numbers within Tityus genus, resulting of these rearrangements. In the scorpion Tityus bahiensis, for example, the diploid number was found to differ across populations of southeastern Brazil, from $2 n=5$ to 19 [19]. This occurs because the mitotic spindles of holocentric system join along the entire length of each chromatid, promoting normal segregation of both fused and fragmented chromosomes during anaphase [20]. In this study, fusions/fissions were found in heterozygosis among specimens of the cytotypes $C(2 n=13), D(2 n=$ 13), $\mathrm{F}(2 \mathrm{n}=12)$ and $\mathrm{G}(2 \mathrm{n}=11)$. In addition, we
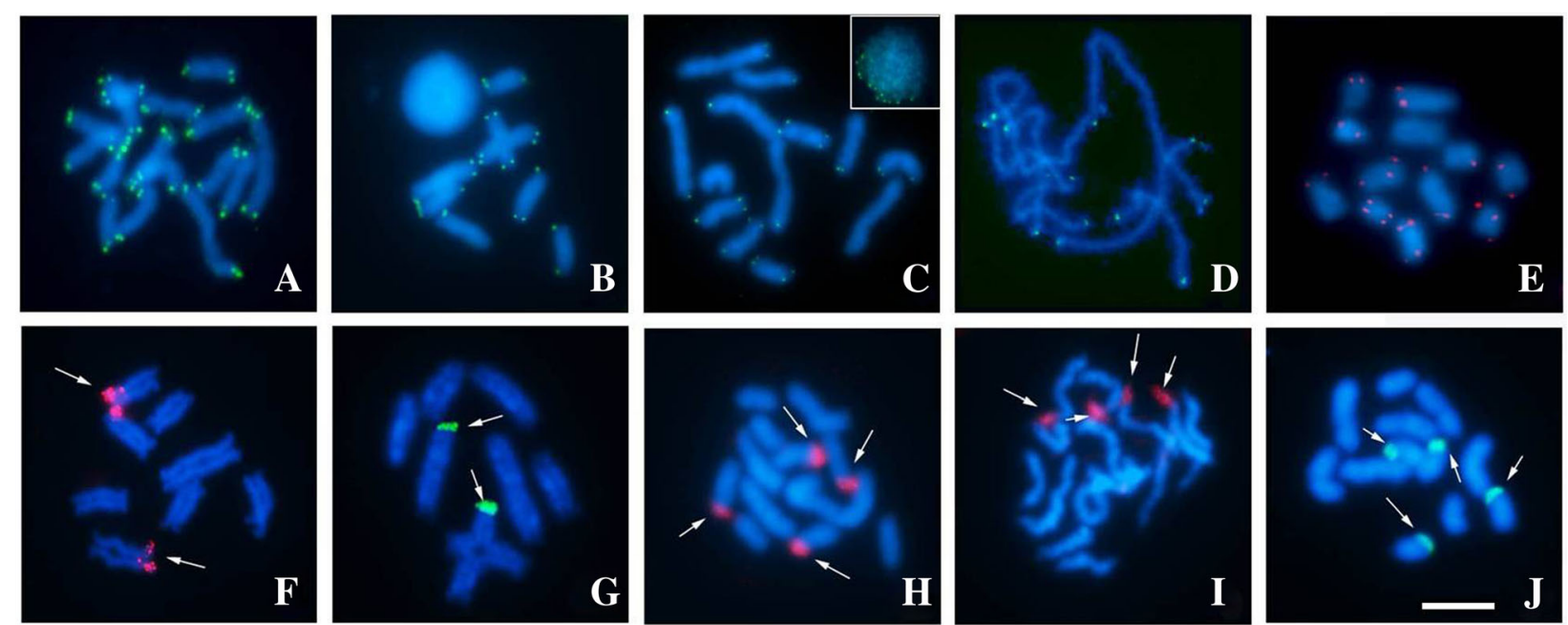

Fig. 3 FISH with TTAGG (a-e) and 45S rDNA (f-j) probes in mitotic (a, c, e, h, i, j) and meiotic (b, d, f, g) chromosomes. a, f cytotype A. b, g Postpachytene in cytotype A, a translocation bearer. $\mathbf{c}, \mathbf{d}, \mathbf{h}$ Cytotype $\mathrm{F}$; the insert in (c) shows a nucleus with telomeres polarized to a single region; in (d) pachytene on the same sample in 3C. e Cytotype C (f) Cytotype E. The arrows in (f-j) point ribosomal sites. Barr $=10 \mu m$ 

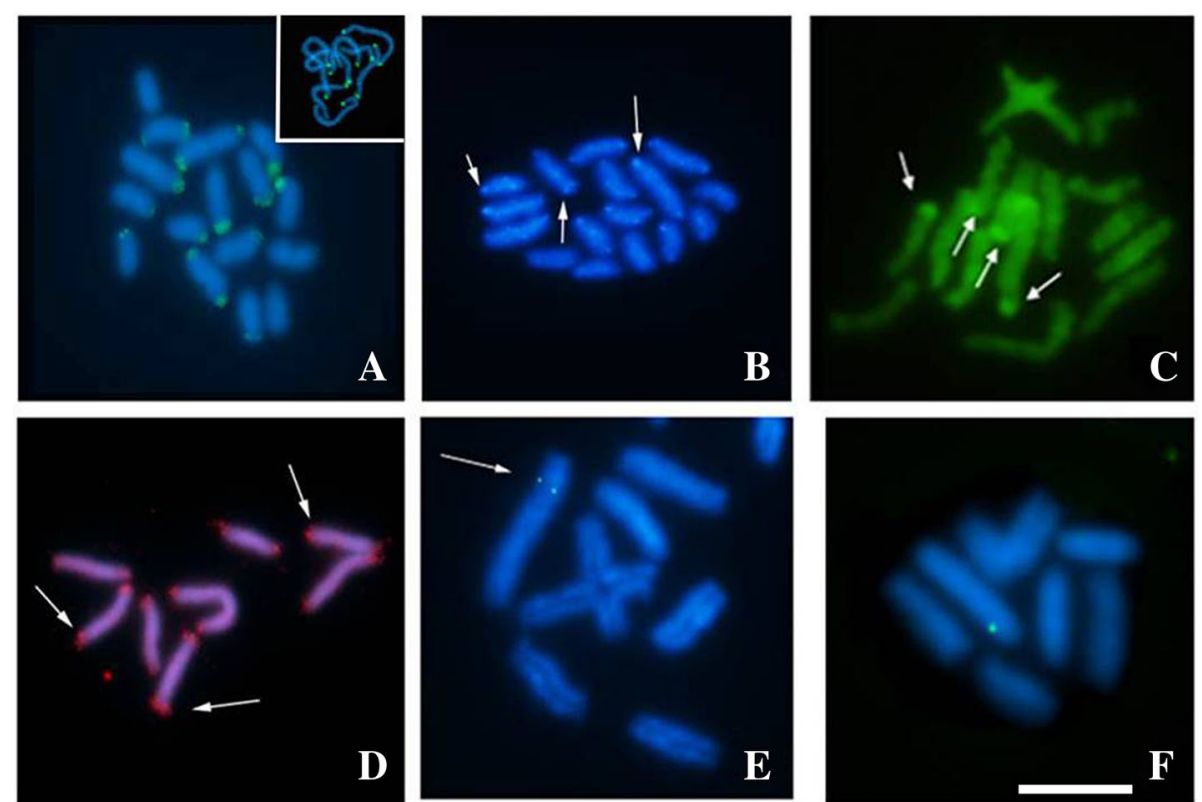

Fig. 4 Heterochromatin and multigenic family mapping in $2 n=16$ specimens. a Cot-1 DNA. The insert in (a) shows a meiotic cell in pachytene. $\mathbf{b}$ DAPI staining. c $\mathrm{CMA}_{3}$ staining. $\mathbf{d}$ FISH H3 histone probe showing terminal hybridization. e U2 snRNA gene maping in a $2 \mathrm{n}=16$ specimen, a translocation bearer. $\mathbf{f} \cup 2$ snRNA gene in a $2 \mathrm{n}=16$ specimen with eight bivalents. Barr $=10 \mu \mathrm{m}$

speculate that chromosome 1 of the cytotypes $\mathrm{C}, \mathrm{F}$ and G may reflect a fusion, based on its extremely-large size and its involvement in trivalent associations during meiosis. The presence of an interstitial C-band would reinforce this hypothesis, as previously suggested for other organisms $[21,22]$. Interestingly, this interstitial Cband was present on extremely large chromosome 1 of three T. obscurus cytotypes, and may be required to stabilize chromosomes resulting from fusion in this species. Absence of interstitial telomeric sites (ITSs) in
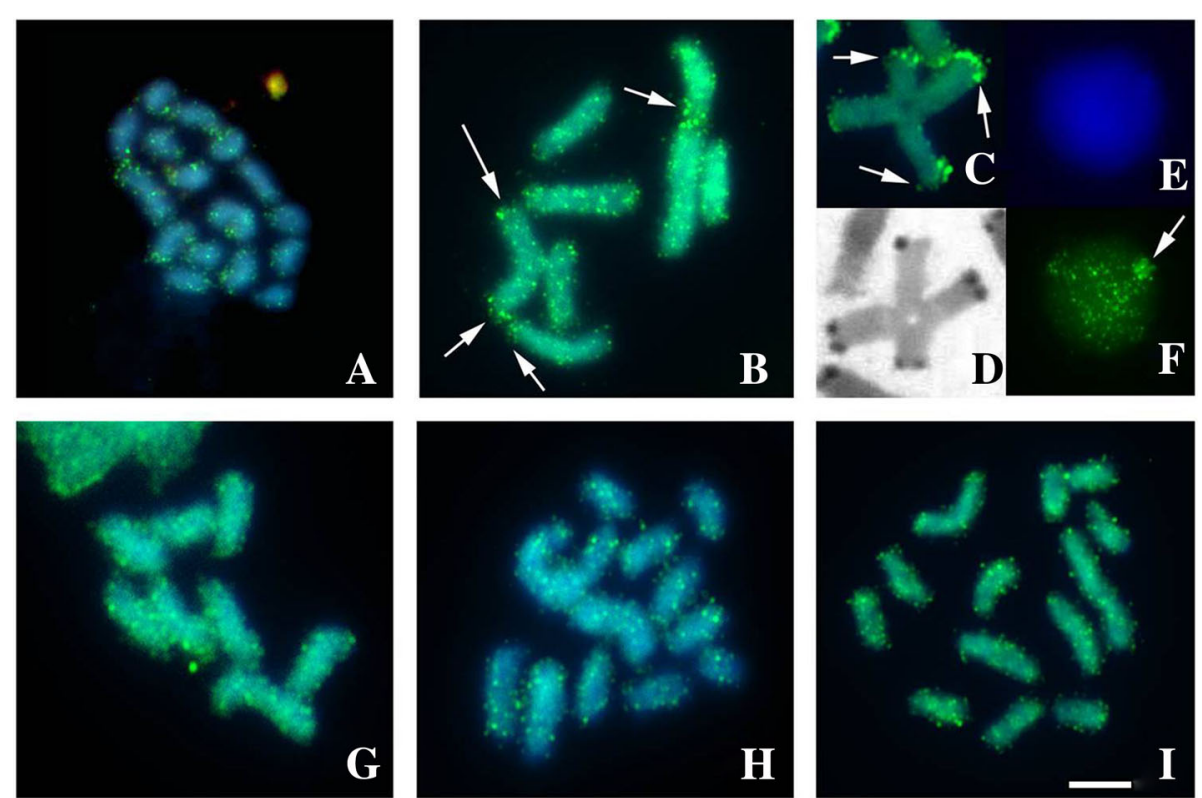

Fig. 5 Mariner mapping in T. obscurus. a-f $2 n=16$, a translocation bearer. a Mitotic metaphase. b Post-pachytene. $\mathbf{c}$ and $\mathbf{d}$ Post-pachytene after FISH and C-banding, with Mariner distribution in the constitutive heterochromatin of quadrivalent. $\mathbf{e}$ and $\mathbf{f}$ Interphase nucleus with packed distribution of Mariner. $\mathbf{g}$ Metaphase I of $2 n=16$ specimen with eight bivalents. $\mathbf{h} 2 n=12$, a translocation bearer. $\mathbf{i} 2 n=13$, a translocation bearer. Barr $=10 \mu \mathrm{m}$ 
the chromosome 1 of cytotype $F(2 n=12)$ can be explained by the small size of the ITS due to the molecular erosion of repetitive sequences, escaping FISH resolution [23] or deletion of telomeres in the original chromosomes [24].

The Fig. 6 shows a schematic interpretation of the karyotype evolution of cytotypes of $T$. obscurus from Santarém. We proposed that the cytotype E $(2 \mathrm{n}=12)$ represent the ancestral karyotype of this population, and that fission events led to the formation of cytotypes $\mathrm{C}$ $(2 n=13)$ and $B(2 n=14)$, whereas the heterozygous fusion of pairs 1 and 3 of ancestral karyotype would have led to the appearance of the cytotype $G(2 n=11)$, which would later originated the cytotype $\mathrm{F}$ through a heterozygous fission of par $2(2 n=12)$. The visualization of TTAGG telomerics repeats only at the end of all chromosomes of cytotype $F(2 n=12)$ suggests that even in those in which fission occurs, there may a telomere reconstitution system. This fact has been previously demonstrated for other taxa bearing holocentric chromosomes, such as Aphids and plants, in which telomerase acts constitutively in the reconstitution of telomeres in fragmented chromosomes [23, 25].

Repetitive sequence mapping enabled us to identify the chromosome pairs involved in the reciprocal translocation observed in a male of cytotype A $(2 n=16)$ from Acará. The first pair was defined by exclusion; both pairs 1 and 2 are large and similar in size. The U2 snRNA gene, which maps to pair 1 , was not included in the translocation, enabling us to conclude that pair 2 is involved in this rearrangement. The other pair was found to bear a $45 \mathrm{~S}$ rDNA cluster, and thus corresponded to chromosome 7. Fertility was not affected by this translocation, since $100 \%$ of the cells in metaphase II had the appropriate haploid number $(\mathrm{n}=8)$, indicating the presence of alternate chromosome segregation. The region between the breakpoints in the quadrivalent was nonsynaptic during pachytene. Schneider et al. [26] also observed this in meiotic cells of four Buthidae, and proposed that it reflected a lack of homology between the rearranged segments. Similar phenomena have been observed in humans [27], pigs [28], boars [29], and in the grasshopper Eyprepocnemis plorans [30].

Our analysis of the geographic distribution of various T. obscurus karyotypes suggests that there is a centralmarginal variation pattern (Fig. 7). According to the model of this kind of variation, populations in the center of a species geographic distribution have a higher genetic diversity than those at the margins [31, 32]. This model was observed in the chromosome inversions patterns of Drosophila willistoni, [33], Trimerotropis pallidipennis [34], and Chironomus plumosus [35], and in fusions of Dichroplus pratensis [36]. In the present work, the Santarém population would be central, while the others (Afuá, Rurópolis, Belém, Moju, Acará, Bragança, Santa Bárbara and Benevides) would be marginal.

\section{Genomic organization of repetitive DNA in holokinetics chromosomes of Tityus obscurus}

In monocentric chromosomes, the centromere is usually surrounded by pericentromeric heterochromatin. It has been proposed that transcriptional inactivity of heterochromatin is required for competence of the centromere and/or that heterochromatin permits centromeric

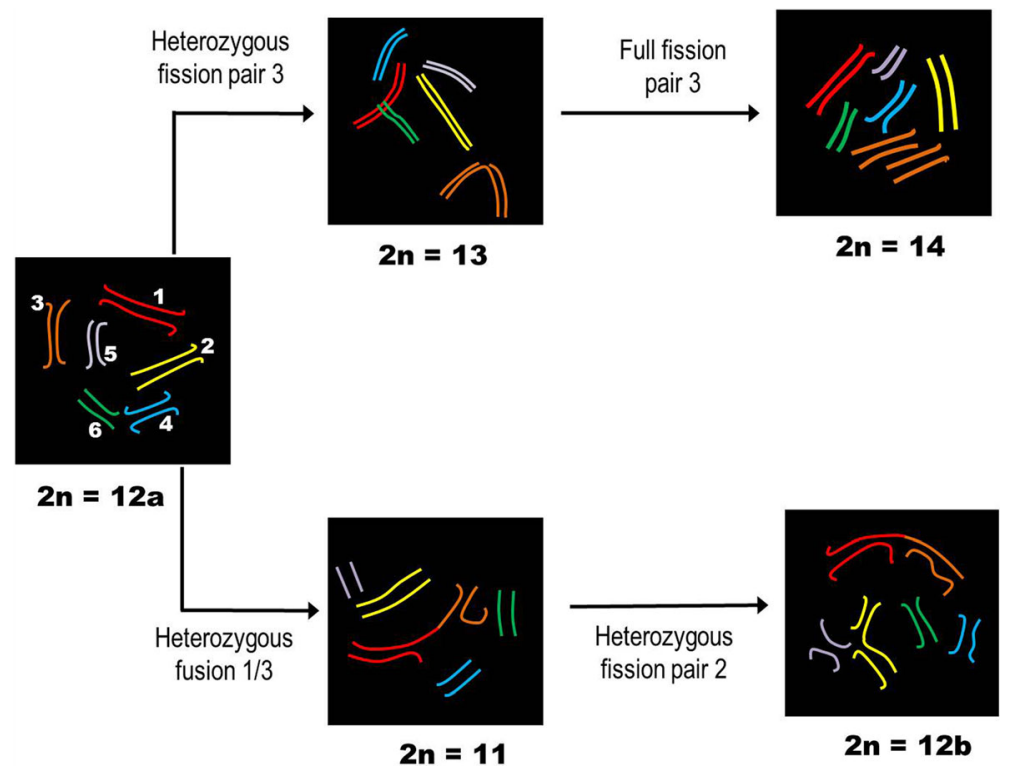

Fig. $\mathbf{6}$ Schematic interpretation of karyotype evolution hypothesis proposed to specimens of Tityus obscurus from Santarém, Brazil 


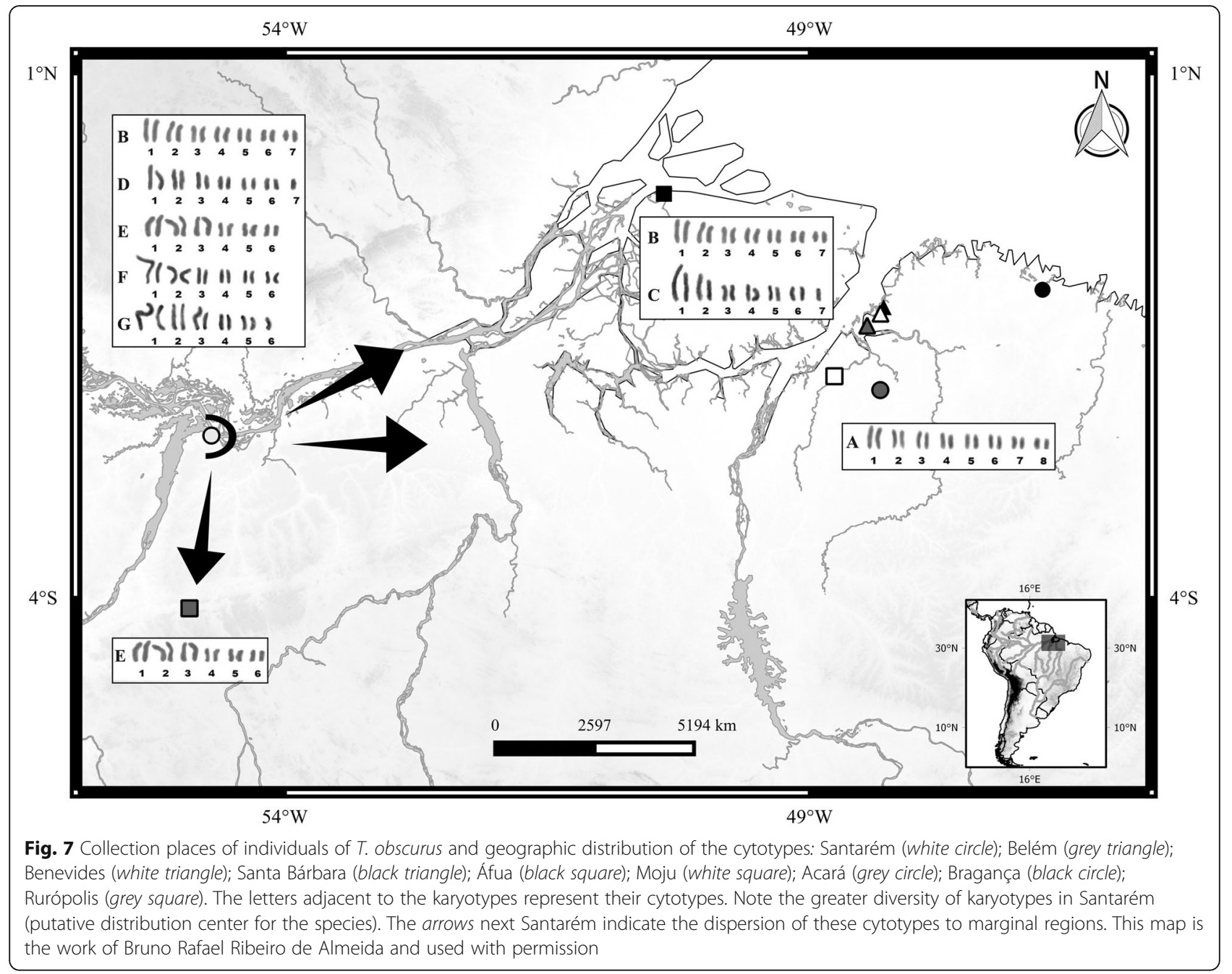

chromatin assembly, perhaps by facilitating expansion of CenH3 domains over flanking regions [37]. Satellite DNAs and transposable elements are main sequences found in the centromeric region [38, 39]. Our result of the mapping of the $C_{0} t-1$ DNA fraction suggests a priori that in Tityus obscurus there is no presence of highly repetitive DNAs associated with centromere domains, since the hybridization signals were observed only in the terminal regions of the meiotic and mitotic chromosomes. This hypothesis is supported by the fact that in most of the animals and plants bearing holocentric chromosomes the presence of centromeric repetitive DNAs was not observed [40]. The only exceptions to this patterns are two species of Rhynchospora (Cyperaceae) for which the centromeric satellite DNA Tyba was described [41]. In Luzula elegans, although cenH3 domains are distributed along the chromosomes, satellite DNAs and retrotransposons did not show expected distribution for wide centromere [42]; in addition, the sequencing of the genome of Luzula elegans and C. elegans showed absence of centromere-associated sequences [41, 43]; in the latter, the incorporation of cenH3 is independent of specific sequences [43]. In insects, absence of centromeric repetitive DNA, may be related to loss of cenH3 protein in holocentrics clades of insects [44].

In Tityus obscurus the presence of two pairs of homologues bearing of the $45 \mathrm{~S}$ rDNA in the terminal region differed from the pattern observed in the other Buthidae, which present ribosomal clusters in one pair of homologues $[11,12]$. Some authors have proposed that the NOR terminal position is necessary for the stability and correct segregation of holokinetic chromosomes during cell division, once decondensed NORs constrictions could promote an interruption in the kinetochore plate [45]. However, this model does not apply to buthid scorpions Androctonus genus, which present interstitial NORs and normal chromosome segregation [6].

The gene encoding Histone H3 was distally distributed in all chromosomes of cytotype A $(2 n=16)$ of $T$. obscurus. Dispersed distributions, such as that observed 
in T. obscurus, have been found on monocentric chromosomes of grasshoppers [46, 47] and in the fish Rachycentron canadum [48]. These studies suggest that the dispersion of Histone $\mathrm{H} 3$ genes can occur by ectopic recombination, transposable elements or circular DNA [46]. The evolutionary significance of dispersed organization of Histone $\mathrm{H} 3$ in T. obscurus is not known; in achiasmatics organisms, such male of Drosophila sp. and females of Lepidoptera, rDNAs and telomeric repeats, respectively, act in recognition and pairing of homologs chromosomes during meiosis [14, 49]. In Luzula elegans, terminal satellites DNA form chromatin bridges between homologous chromosomes to ensure correct segregation during inverted meiosis [50]. In T. obscurus clusters Histone H3 can perform similar function.

This is the first study mapping the Mariner transposon in Arachnida. In our sample, this transposon was either dispersed throughout the euchromatin (in most specimens) or packed in the heterochromatin (in the $2 n=16$ translocation bearer). The chromosomal distribution of this transposable element is extremely variable among organisms. In beetles, for example, Mariner was found only in heterochromatin [51], while in grasshoppers, it was reportedly restricted to euchromatin [52]. TEs tend to accumulate in genomic regions that have low recombination rates, such as pericentromeric heterochromatin, B chromosomes and sex chromosomes [53-55]. This pattern reflects a strong selection pressure against the deleterious effects of recombination in these regions [55]. The presence of Mariner in the euchromatin of $T$. obscurus can be partly explained by the absence of recombination during male meiosis, which is achiasmatic [19].

Repetitive sequences were concentrated at the terminal regions, as shown by our analyses of C-banding, telomeric sequences, Cot-1 DNA, 45S rDNA, H3 histone genes, and (in the $2 n=16$ individual heterozygous for the translocation) Mariner transposons, while an expressed multigene family (U2 snRNA) mapped to an interstitial region. Our results are consistent with previous reports that repetitive sequences tend to be found in holocentric chromosomes terminals [56, 57], while single genes are always distributed throughout the genome [58-60]. Thus, the regions where the repetitive sequence accumulates (here, the terminal regions in $T$. obscurus) must somehow differ from the rest of the genome. While the kinetochore was believed to extend along the poleward face of the metaphase chromosome in holocentric chromosomes [61], Heckmann et al. [45] showed that this is not necessarily true, as the centromeric regions of Luzula elegans extend along most of the chromosome, but do not cover the terminal regions. Benavente [62] performed an ultrastructural analysis of chromosome of scorpion Tityus bahiensis and demonstrated that they are only partially covered by kinetochore. Based on our present results, we propose that the chromosomes of $T$. obscurus are not entirely holocentric; instead, we believe that the distal regions, with their accumulations of repetitive sequences, flanking the kinetochore, but are not covered by it.

\section{Conclusions}

Chromosomal variability found in T. obscurus is due to rearrangements of the type fusion/fission and reciprocal translocations in heterozygous. These karyotype differences follow a geographical pattern and may be contributing to reproductive isolation between the analyzed populations. Our results also demonstrate high mobility of histone $\mathrm{H} 3$ genes that can act in recognition, pairing and segregation of homologue chromosomes. In contrast, other multigene families (45S rDNA and $\mathrm{U} 2$ snRNA) have conserved distribution among individuals, and showed to be reliable markers to elucidate chromosomal rearrangements in $T$. obscurus. $C_{0} t-1$ DNA fraction is terminally distributed on all pairs in T. obscurus, suggesting the absence of repetitive DNA associated with the wide centromere. The accumulation of repetitive sequences in distal regions of T. obscurus chromosomes suggests that distal portions of chromosome are not covered by the kinetochore.

\section{Methods}

\section{Sample}

Adult Tityus obscurus were captured in municipalities of Pará State, Brazil. Information on sex and collection sites of the individuals is described in Table 1 and Fig. 7). The specimens were deposited in the collection of Medical Entomology Laboratory and Venomous Arthropods of Tropical Medicine Center of UFPA.

\section{Karyotype analysis}

Chromosome preparations were generated as described by [19]. Gonads were submitted to hypotonic treatment with $0.075 \mathrm{M} \mathrm{KCl}$ for $20 \mathrm{~min}$ and then fixed in acetic

Table 1 Details on the sample used in this study

\begin{tabular}{lll}
\hline $\mathrm{N}$ & Locality & Geographical coordinate \\
\hline 1 male/3 females & Belém, PA, Brasil & $1^{\circ} 24^{\prime} 16.29^{\prime \prime} \mathrm{S} / 48^{\circ} 27^{\prime} 12.29^{\prime \prime} \mathrm{O}$ \\
1 female & Santa Bárbara, PA, Brasil & $1^{\circ} 13^{\prime} 40.15^{\prime \prime} \mathrm{S} / 48^{\circ} 17^{\prime} 46.53^{\prime \prime O}$ \\
2 males/10 & Benevides, PA, Brasil & $1^{\circ} 17^{\prime} 23.33^{\prime \prime} \mathrm{S} / 48^{\circ} 19^{\prime} 35.69^{\prime \prime O}$ \\
$\begin{array}{l}\text { females } \\
1 \text { female }\end{array}$ & $1^{\circ} 53^{\prime} 06.64^{\prime \prime} \mathrm{S} / 48^{\circ} 45^{\prime} 55.52^{\prime \prime} \mathrm{O}$ \\
2 males & Moju, PA, Brasil & $2^{\circ} 01^{\prime} 03.79^{\prime \prime} \mathrm{S} / 48^{\circ} 1910.42^{\prime \prime O}$ \\
1 male & Acará, PA, Brasil & $1^{\circ} 03^{\prime} 41.83^{\prime \prime} \mathrm{S} / 46^{\circ} 46^{\prime} 58.84^{\prime \prime O}$ \\
2 males/4 females & Afuá, PA, Brasil & $0^{\circ} 08^{\prime} 51.08^{\prime \prime} \mathrm{S} / 50^{\circ} 23^{\prime} 24.25^{\prime \prime O}$ \\
5 males/2 females & Santarém, PA, Brasil & $2^{\circ} 27^{\prime} 04.27^{\prime \prime} \mathrm{S} / 54^{\circ} 42^{\prime} 04.63^{\prime \prime O}$ \\
2 male/1 female & Rurópolis, PA, Brasil & $4^{\circ} 06^{\prime} 02.68^{\prime \prime} \mathrm{S} / 54^{\circ} 54^{\prime} 34.65^{\prime \prime O}$ \\
\hline
\end{tabular}


acid: methanol solution (3: 1 ratio) overnight. Fragments of gonads were macerated in $60 \%$ acetic acid, and cell suspension was spread on slides; after drying at $45{ }^{\circ} \mathrm{C}$, chromosomes were stained with Giemsa 5\%. Chromosomal measurements were performed through MicroMeasure software version 3.3 for Windows [63], and classified according to size in extremely large (EL), large (L), medium (M) and small (S). The karyotypes were organized using the Adobe Photoshop version 4.0 software. C-banding [64] and fluorochrome banding using 4,6-diamidino-2-phenylindole (DAPI) [65] and Chromomycin $\mathrm{A} 3\left(\mathrm{CMA}_{3}\right)[66]$ were performed according to the mentioned references.

\section{Synaptonemal complex analisys}

Synaptonemal complex spreading was obtained as described by [67] with modifications. Gonads were maintained in Hanks solution for $10 \mathrm{~min}$. Then they were macerated in $100 \mathrm{mM}$ sucrose solution with the aid of needles. The cell suspension was spread on slides previously coated with paraformaldehyde $2 \%$ and incubated in humid chamber for $2 \mathrm{~h}$ at room temperature. After this, slides were washed in $0,08 \%$ Photo-flo solution for five minutes and stored at $-80{ }^{\circ} \mathrm{C}$. For visualization of the synaptonemic complex, slides were stained with a $50 \%$ silver nitrate solution, according to [68].

\section{Probes}

The genomic DNA of one T. obscurus female was extracted with GenEluteMammalian Genomic DNA Miniprep Kit (Sigma-Aldrich, St. Louis, MO, USA), and was used as template for isolation of repetitive sequences. The telomeric motif (TTAGG) was amplified by PCR using the $(\text { TTAGG })_{5}$ and $(\text { CCTAA })_{5}$ complementary primers [69]. The genes encoding H3 histones and U2 snRNA were isolated as described by [70] using the primers: 5' -ATG GCT CGT ACC AAG CAG AC(ACG) GC-3' and 5'-ATA TCC TT(AG) GGC AT(AG) AT(AG) GTG AC-3' for H3 Histone; 5'-TCT CGG CCT (AT)(AT)T GGC TAA-3' and $5^{\prime}$-G(AC)G GTA (GC)TG CAA TAC CGG-3' for U2 snRNA. Mariner transposon partial sequence was obtained as described by [71] using primers MAR-188 F (5'-ATC TGR AGC TAT AAA TCA CT-3') e MAR-251R (5-CAA AGA TGT CCT TGG GTG TG-3'). The PCR products were directed used as probes for FISH, after being analysed in agarose gel $1 \%$. To construct the $45 \mathrm{~S}$ rDNA probe, we used the pTa71 plasmid, which contains the genes 5.8S, $18 \mathrm{~S}, 28 \mathrm{~S}$ and their respective intergenic spacers, isolated from genome of Triticum aestivum [72].

The $C_{0} t-1$ DNA was obtained according to [73]. Initially, $500 \mu \mathrm{L}$ of genomic DNA of Tityus obscurus (400 $\mathrm{ng} / \mu \mathrm{L}$ at $\mathrm{NaCl} 0,3 \mathrm{M}$ ) were autoclaved for 3 to $5 \mathrm{~min}$, and then denatured at $95{ }^{\circ} \mathrm{C}$ for $10 \mathrm{~min}$. DNA was treated for 1 min with the enzyme S1 Nuclease, and subsequently frozen in liquid nitrogen. Afterwards it was precipitated using phenol/chloroform and ice-cold absolute ethanol, and kept in the freezer at $-80{ }^{\circ} \mathrm{C}$ for 30 min. Then, the DNA was resuspended in ultrapure water and stored at $-20{ }^{\circ} \mathrm{C}$ until use.

Probes were labeled by nick translation according to the kit available. All probes were labeled with digoxigenin-14-dUTP (Roche, Mannheim, Germany). Alternatively, some telomeric, Histone $\mathrm{H} 3$ and rDNA probes were labeled with biotin-11-dATP (Invitrogen, San Diego, CA, USA).

\section{FISH}

Fluorescence in situ Hybridization (FISH) was performed as described by [74] with modifications. Briefly, the slides were incubated in RNAse and Pepsin solution for $1 \mathrm{~h}$ and $15 \mathrm{~min}$, respectively, both at $37{ }^{\circ} \mathrm{C}$. After, slides were fixed in $4 \%$ paraformaldehyde and dehydrated in ethanol series (70, 90 and 100\%). Hybridization solution containing probes was denatured to $100{ }^{\circ} \mathrm{C}$, spread on the slides, which were covered with coverslips. Chromosomal DNA was denatured to $70^{\circ} \mathrm{C}$. Hybridization occurred at $37{ }^{\circ} \mathrm{C}$, overnight. Probes were visualized with Avidin-Cy3 or Anti-Digoxigenin-FITC. Chromosomes were counterstained with DAPI (Vectashield; Vector, Burlingame, California, USA).

\section{Abbreviations \\ Cot-1 DNA: DNA enriched for highly and moderately repetitive DNA sequences; $\mathrm{CH}$ : Constitutive heterocromatin; $\mathrm{CMA}_{3}$ : Chromomycin $\mathrm{A} 3$; DAPI: 4,6-diamidino-2-phenylindole; PCR: Polymerase chain reaction; SC: Synaptonemal complex; snRNA gene: Small nuclear RNA gene}

\section{Acknowledgements}

This study is part of Master dissertation of BRRA who was a recipient of a CNPq Scholarship in Genetics and Molecular Biology, UFPA. The authors are grateful to members of the team of cytogenetics laboratory UFPA in the field work and chromosomal preparations. To MSc. Jorge Rissino, to Msc. Shirley Nascimento and Maria da Conceição for assistance in laboratory work. Sample collection was authorized by Sistema de Autorização e Informação em Biodiversidade (SISBIO), Instituto Chico Mendes de Conservação da Biodiversidade (ICMBio) and Secretaria de Estado de Meio Ambiente do Pará (SEMA-PA).

\section{Funding}

The Fundação Amazônia Paraense (FAPESPA) for financial supported a project coordinated by JC Pieczarka (Edital Vale - ICAAF 064/2011). The Banco Nacional de Desenvolvimento Economico e Social - BNDES

(2.318.697.0001) for financial support on a project coordinated by JCP. The Coordenação de Aperfeiçoamento de Pessoal de Nivel Superior (CAPES) for financial support on a project coordinated by CYN. JCP (308401/2013-1) and CYN (308428/2013-7) are granted as CNPq researchers.

\section{Availability of data and materials}

Data can be requested from the corresponding author.

\section{Authors' contributions}

Coordinated the study: JCP. Conceived, designed and performed the experiments: BRRA, JCP, SSRMP, RCRN, CYN. Performed meiotic analysis: RCRN, MJCR, BRRA. Sample collection and taxonomic identification species: PPOP, JCS, BRRA, MJCR. Analyzed the data: BRRA, SSRMP, RCRN, JCP, CYN, MJCR, PPOP, JSC. All authors read and approved the final manuscript. 


\section{Competing interests}

The authors declare that they have no competing interests.

\section{Consent for publication}

Not applicable.

\section{Ethics approval}

The authors declare that all experiments performed in accordance with the ethical standards established in Brazilian law. All institutional and national guidelines for the care and use of laboratory animals were followed. This research was approved by the "Comitê de Ética em Pesquisa com animais de experimentação" (Ethics Committee in Research with experimental animals) from the Universidade Federal do Pará, reference number 68-2015. JCP has a permanent field permit, number 13248 from "Instituto Chico Mendes de Conservação da Biodiversidade". The Cytogenetics Laboratory from UFPa has a special permit number 19/2003 from the Ministry of Environment for samples transport and 52/2003 for using the samples for research.

\section{Publisher's Note}

Springer Nature remains neutral with regard to jurisdictional claims in published maps and institutional affiliations.

\section{Author details}

${ }^{1}$ Laboratório de Citogenética, Centro de Estudos Avançados da Biodiversidade, Instituto de Ciências Biológicas, Universidade Federal do Pará, Avenida Augusto Corrêa, n01, Av. Perimetral, s/n. Guamá, 66075-900 Belém, Pará, Brazil. ${ }^{2}$ Instituto Federal de Educação, Ciência e Tecnologia de Goiás, Campus Valparaíso de Goiás, BR-040, km 6, Avenida Saia Velha, S/N, Área 8, Parque Esplanada V, 72876-601 Valparaíso de Goiás, Goiás, Brazil. ${ }^{3}$ Laboratório de Entomologia Médica e Artrópodes Peçonhentos, Núcleo de Medicina Tropical, Universidade Federal do Pará, Avenida Generalíssimo Deodoro, 92, 66055-240 Belém, Pará, Brazil.

\section{Received: 16 October 2016 Accepted: 25 March 2017}

\section{Published online: 17 April 2017}

\section{References}

1. Melters DP, Paliulis LV, Korf IF, Chan SWF. Holocentric chromosome convergent evolution, meiotic adaptations, and genomic analysis. Chromosome Res. 2012;20:593-79.

2. Cook LG. Extraordinary and extensive karyotypic variation: a 48-fold range in chromosome number in the gall-inducing scala insect Apiomorpha (Hemiptera: Coccoidea:Eriococcidae). Genome. 2000:43:263-55.

3. Chung KS, Weber JA, Hipp AL. Dynamics of chromosome number and genome size variation in acyogeneically variable sedge (Carex scoparia var, scoparia, Cyperaceae). Am J Bot. 2011;98:129-2.

4. Guerra M, Cabral G, Cuacos M, González-García M, González-Sanchez M, Vega J, Puertas MJ. Neocentrics and Holokinetics (Holocentrics): chromosomes out of the cetromeric rules. Cytogenet Genome Res. 2010; 129.96-82.

5. Král J, Kováč L, Štáhlavský F, Lonský P, L'Uptáčik. The first karyotype study in palpigrades, a primitive order of arachnids (Arachnida: Palpigradi). Genetica. 2008;134:87-78.

6. Sadílek D, Nguyen P, Koç H, Kovařík F, Yagmur EA, Štáhlavský. Molecular cytogenetics of Androctonus Scorpions: na oásis of calm in the turbulent karyotype evolution of the diverse family Buthidae. Biol J Linnean Soc. 2015; 115:76-69.

7. Moustafa MA, Alaa AM, Sarhan MH, Yaseen AE. Chromosomal studies on four egyptian scorpion species of genus Androctonus (Family Buthidae). Cytologia. 2005;70:165-1

8. Shanahan CM. Cytogenetics of Australian Scorpions I. Interchange polymorphism in the family Buthidae. Genome. 1989;32:889-2.

9. Mola LM, Rebagliati PJ, Gil SGR, Adilardi RS. Variaciones meióticas y evolución cromosómica en insectos y arácnidos con cromosomas holocinéticos. J Bas Appl Genet. 2011;22:6-1.

10. Štáhlavský F, Koç H, Yağmur EA. The first record of karyotypes in Leiurus abdullahbayrami and Compsobuthus mathiesseni (Scorpiones, Buthidae) from Turkey. North-West J Zool. 2014;10:358-5.
11. Mattos VF, Carvalho LS, Cella DM, Schneider MC. Location of 455 ribosomal genes in mitotic and meiotic chromosomes of Buthid scorpions. Zoolog Sci. 2014;31:607-3

12. Adilardi RS, Ojanguren-Affilastro AA, Mattoni Cl, Mola LM. Male and female meiosis in the mountain scorpion Zabius fuscus (Scorpiones, Buthidae): heterocromatin, rDNA and TTAGG telomeric repeats. Genetica. 2015;143: 401-393.

13. Hill CA, Guerrero FD, Van Zee JP, Geraci NS, Walling JG, Stuart JJ. The position of repetitive DNA sequence in the southern cattle tick genome permits chromosome identification. Chromosome Res. 2009;17:89-77.

14. Rego A, Marec F. Telomeric and interstitial telomeric sequences in holokinetic chromosome of Lepidoptera: Telomeric DNA mediates association between postpachytene bivalents in achiasmatic meiosis of female. Chromosome Res. 2003;11:694-81.

15. Papeschi AG, Mola LM, Bressa MJ, Greizerstein EJ, Lía V, Poggio L. Behaviour of rings bivalents in holokinetic systems: alternative sites of spindle attachament in Pachylis argentinus and Nezara viridula (Heteroptera). Chromosome Res. 2003;11:733-25.

16. Fujiwara H, Osanai M, Matsumoto T, Kojima KK. Telomere-specific non-LTR retrotransposons and telomere maintenance in the silkworm, Bombyx mori. Chromosome Res. 2005;13:467-55.

17. Souza CAR, Candido DM, Lucas SM, Brescovit AD. On the Tityus stigmurus complex (Scorpiones, Buthidae). Zootaxa. 1987;2009:38-1.

18. Mattos VF, Cella DM, Carvalho LS, Candido DM, Schneider MC. High chromosome variability and the presence of multivalent associations in buthid scorpions. Chromosome Res. 2013;21:136-21.

19. Schneider MC, Zacaro AA, Pinto-da-Rocha R, Candido DM, Cella DM. Complex meiotic configuration of the holocentric chromosomes: the intriguing case of the scorpion Tityus bahiensis. Chromosome Res. 2009;17:898-83.

20. Mola LA, Papeschi AG. Holokinetic chromosome an glance. J Bas Appl Genet. 2006;17:33-17.

21. Blackman RL, Spencer JM, Normark BB. High diversity structurally heterozygous karyotypes and rDNA arrays in parthenogenetic aphids of the genus Trama (Aphididae: Lachininae). Heredity. 2000;84:260-54.

22. Menezes RST, Silva TM, Carvalho AF, Andrade-Souza V, Silva JG, Costa MA. Numerical and structural chromosome variation in the swarm-founding wasp Metapolybia decorate Gribodo 1896 (Hymenoptera, Vespidae). Genetica. 2013:141:280-73.

23. Mohan NK, Rani S, Kulashreshta PS, Kadandale JS. Characterization of TTAGG telomeric repeats, their interstitial occurrence and constitutively active telomerase in the mealybug Planococcus lilacinus. Chromosoma. 2010;120:175-65.

24. Poggio MG, Gaspe MS, Papeschi AG, Bressa MJ. Cytogenetic study in a mutant of Triatoma infestans (Hemiptera, Reduviidae) carryng a spontaneous autosomal fusion and an extra chromosome. Cytogenet Genome Res. 2013;134:51-44.

25. Jankowska M, Fuchs J, Klocke E, Fojtová M, Polanská P, Fajkus J, Schubert V, Houben A. Holokinetic centromeres and efficient telomere healing enable rapid karyotype evolution. Chromosoma. 2015;124:528-19.

26. Schneider MC, Mattos VF, Carvalho LS, Cella DM. Organization and behavio of the synaptonemal complex during achiasmatic meiosis of four buthid scorpions. Cytogenet Genome Res. 2015:144:347-1.

27. Oliver-Bonet M, Benet J, Sun F, Navarro J, Abad C, Liehr T, Starkes H, Greene C, Ko E, Martin RH. Meiotic studies in two human reciprocal translocations and their association with spermatogenic failure. Hum Reprod. 2005;20:688-3.

28. Gustavsson I, Switonski M, Larsson K, Ploen L, Hojeri K. Chromosome banding studies and synaptonemal complex analyses of four reciprocal translocations in the domestic pig. Hereditas. 1988;109:184-69.

29. Gabriel-Robez O, Jaafar H, Ratomponirina C, Boscher J, Bonneau J, Popescu $\mathrm{CP}$, Rumpler Y. Heterosynapsis in a heterozygous fertile boar carrier of a 3;7 translocation. Chromosoma. 1988:97:32-27.

30. Arana P, Santos JL, Henriques-Gil N. Interference relationships in grasshopper reciprocal translocation heterozygotes. Heredity. 1987:59:85-93.

31. Eckert CG, Samis KE, Lougheed SC. Genetic variation across species' geographical ranges: the central-marginal hypothesis and beyond. Mol Ecol. 2008;17:1188-70.

32. Tahvanainen $\mathrm{P}$, Alpermann TJ, Fiqueroa RI, John U, Hakanen $\mathrm{P}$, Nagai $\mathrm{S}$, Blomster J, Kremp A. Patterns of post-glacial genetic differentiation in marginal populations of a marine microalga. Plos One. 2012;7:12.

33. Cunha AB, Dobzhansky T. A further study of chromosomal polymorphism in Drosophila willistoni in its relation to the environment. Evolution. 1954:8:134-19. 
34. Goni B, Vaio ES, Beltrami M, Leira MS, Crivel M, Panzera F, Castellanos P, Basso A. Geographic patterns of chromosomal variation in populations of the grasshopper (Trimerotropis pallidipennis) from south Argentina. Can J Genet Cytol. 1985;27:271-59.

35. Michailova P, Krastanov B, Matena J. Chromosomal polymorphism of Chironomus plumosus (Linnaeus, 1758) (Diptera: Chironomidae) from Bulgaria (Parzadjik region) and the Czech Republic (Ceske Budejovice region). Comp Cytogenet. 2008;2:65-57.

36. Colombo PC. Micro-evolution in grasshoppers mediated by polymorphic Robertsonian translocations. J Insect Sci. 2013;13:22-1.

37. Malik HS, Henikoff S. Major evolutionary transitions in centromere complexity. Cell. 2009;138:1082-607.

38. Ferreira IA, Martins C. Physical chromosome mapping of repetitive DNA sequences in Nile tilapia Oreochromis niloticus: evidence for a differential distribution of repetitive elements in the sex chromosomes. Micron. 2008;39:418-1.

39. Carvalho NDM, Carmo E, Neves RO, Schneider CH, Gross MC. Differential repetitive DNA composition in the centromeric region of chromosome of Amazonian lizard species in the family Teiidae. Comp Cytogenet. 2016;10:217-03.

40. Marques A, Pedrosa-Harand A. Holocentromere identity: from the typical mitotic linear structure to the great plasticity of meiotic holocentromeres. Chromosoma. 2016;125:681-69

41. Ribeiro T, Marques A, Novák P, Schubert V, Vanzela ALL, Macas J, Houben A Pedrosa-Harand A. Centromeric and non-centromeric satellite DNA organization differs in holocentric Rhynchospora species. Chromosoma. 2016. doi:10.1007/s00412-016-0616-3.

42. Heckmann S, Macas J, Kumke K, Fuchs J, Schubert V, Ma L, Novák P, Neumann P, Taudien S, Platzer M, Houben A. The holocentric species Luzula elegans shows interplay between centromere and large-scale genome organization. Plant J. 2013;73:565-55.

43. Gassmann R, Rechtsteiner A, Yuen KW, Muroyama A, Egelhofer T, Gaydos L, Barron F, Maddox P, Essex A, Monen J, Ercan S, Lieb JD, Oegema K, Strome $S$, Desai $A$. An inverse relationship to germiline transcription defines centromeric chromatin in C. elegans. Nature. 2012;484:537-84.

44. Drinnenberg IA, Young D, Henikoff S, Malik HS. Recurrent loss of cenH3 is associated with independent transitions to holocentricity in insects. Elife. 2014;3:19.

45. Heckmann S, Schroeder-Reiter E, Kumke K, Ma L, Nagaki K, Murata M, Wanner G, Houben A. Holocentric chromosomes of Luzula elegans are characterized by a longitudinal centromere groove, chromosome bending and a terminal Nucleolus Organizer Region. Cytogenet Genome Res. 2011; 134:228-0.

46. Bueno D, Palacios-Gimenez OM, Cabral-de-Mello DC. Chromosomal mapping of repetitive DNAs in the grasshopper Abracris flavolineata reveal possible ancestry of the $\mathrm{B}$ chromosome and $\mathrm{H} 3$ Histone spreading. Plos one. 2013:8:6

47. Palacios-Gimenez OM, Marti DA, CabraldeMello DC. Neo-sex chromosomes of Ronderosia bergi: insight into the evolution of sex chromosomes in grasshoppers. Chromosoma. 2015;124:365-53.

48. Costa GWWF, Cioffi MB, Bertollo LAC, Molina BWE. Unusual dispersion of histone repeats on the whole chromosomal complement and their colocalization with ribosomal genes in Rachycentron canadum (Rachycentridae, Perciformes). Cytogenet Genome Res. 2014;144:67-2.

49. McKee BD, Karpen $\mathrm{GH}$. Drosophila ribosomal RNA genes function as an pairing X-Y site during meiosis. Cell. 1990;61:72-61.

50. Heckmann S, Jankowska M, Schubert V, Kumke K, Ma W, Houben A Alternative meiotic chromatid segregation in the holocentric plant Luzula elegans. Nat Comun. 2014;5:4979.

51. Oliveira SG, Cabral-de-Mello DC, Moura RC, Martins C. Chromosomal organization and evolutionary history of Mariner transposable elements in Scarabaeinae coleopterans. Mol Cytogenet. 2013;6:54.

52. Palacios-Gimenez OM, Bueno D, Cabral-de-Mello DC. Chromosomal mapping of two Mariner-like in the grasshoper Abracris flavolineata (Orthoptera: Acrididae) reveals enrichment in euchromatin. Eur J Entomol. 2014;111:334-29.

53. Valente GT, Mazzuchelli J, Ferreira IA, Poletto AB, Fantinati BEA, Martins C. Cytogenetic mapping of the retroelements Rex1, Rex3 and Rex6 among cichlid fish: new insights on the chromosomal distribution of transposable elements. Cytogenet Genome Res. 2011;133:42-34

54. Oliveira SG, Moura RC, Martins C. B chromosome in the beetle Coprophanaeus cyanescens (Scarabaeidae): emphasis in the organization of repetitive DNA sequences. BMC Genet. 2012;13:96.
55. Bartolomé C, Maside X, Charlesworth B. On the abundance and distribution of transposable elements in the genome of Drosophila melanogaster. Mol Biol Evol. 2012;19:937-26.

56. Severi-Aguiar GDC, Azeredo-Silveira MTV. Localization of rDNA sites in holocentric chromosomes of three species of triatomines (Heteroptera, Triatominae). Genet Mol Res. 2005;4:709-4.

57. Monti V, Manicardi GC, Mandrioli M. Cytogenetic and molecular analysis of the holocentric chromosomes of the potato aphid Macrosiphum euphorbiae (Thomas, 1878). Comp Cytogenet. 2011;5:172-63.

58. Pringle EG, Baxter SW, Webster CL, Papanicolaou A, Lee SF, Jiggins CD. Synteny and chromosome evolution in the Lepidoptera: evidence from mapping in Heliconius melpomene. Genetics. 2007;177:426-17.

59. Beldade P, Saenko SV, Pul N, Long AD. A gene-based linkage map for Bicyclus anynana butterflies allows for a comprehensive analysis of synteny with the Lepidopteran reference genome. PLoS Genet. 2009;5:2.

60. Baxter SW, Davey JW, Johnston JS, Shelton AM, Heckel DG, Jiggins CD, Blaxter ML. Linkage mapping and comparative genomics using nextgeneration RAD sequencing of a non-model organism. PLoS One. 2011;6:4.

61. Hipp AL, Escudero M, Chung K-S. Holocentric Chromosomes. In: Brenner S and Miller JH editors. Brenner's Encyclopedia of Genetics. Academic Press, 2013:10.1016/B978-0-12-374984-0.00723-3.

62. Benavente R. Holocentric chromosome of arachnids: presence of kinetochore plates during meiotic divisions. Genetica. 1982;59:27-3.

63. Reeves A, Tear J. Micromeasure for Windows, version 3.3. http://rydberg. biology.colostate.edu/MicroMeasure/.

64. Sumner AT. A simple technique for demonstrating centromeric heterochromatin. Exp Cell Res. 1972;75:306-4.

65. Pieczarka JC, Nagamachi CY, Souza ACP, Milhomem SSR, Castro RR, Nascimento AL. An adaptation to DAPI-banding to fishes chromosomes. Caryologia. 2006;59:46-3.

66. Schweizer D. Simultaneous fluorescent staining of $\mathrm{R}$ bands and specific heterochromatic regions (DA/DAPI bands) in human chromosomes. Cytogenet Cell Genet. 1980;27:193-0.

67. Vieira A, Santos JL, Rufas JS. Relationship between incomplete synapsis and chiasma localization. Chromosoma. 2009;118:389-77.

68. Howell WM, Black DA. Controlled silver-staining of nucleolus organizer regions with a protective colloidal developer: a 1-step method. Experientia. 1980;36:1015-4.

69. Sahara K, Marec F, Traut F. TTAGG telomeric repeats in chromosome some insects and others arthropods. Chromosome Res. 1999;7:460-49.

70. Colgan DJ, McLauchlan A, Wilson GDF, Livingston SP, Edgecombe GD, Macaranas J, Cassis G, Gray MR. Histone H3 and U2 snRNA DNA sequences and arthropod molecular evolution. Austral J Zool. 1998;46:437-19.

71. Lampe DJ, Witherspoon DJ, Soto-Adames FN, Robertson HM. Recent horizontal transfer of mellifera subfamily Mariner transposons into insect lineages representing four different orders shows that selection acts only during horizontal transfer. Mol Biol Evol. 2003;20:562-54.

72. Gerlach WL, Bedbrook JR. Cloning and characterization of ribosomal RNA genes from wheat and barley. Nucleic Acids Res. 1979;7:1885-69.

73. Zwick MS, Hanson RE, McKnight TD, Nurul-Islam-Faridi M, Stelly DM. A rapid procedure for the isolation of Cot-1 DNA from plants. Genome. 1997:40: 142-32.

74. Cabral-de-Mello DC, Moura RC, Martins C. Chromosomal mapping of repetitive DNAs in the beetle Dichotomius geminates provide the first evidence for an association of $5 \mathrm{~S}$ rRNA and histone $\mathrm{H} 3$ genes in insects, and repetitive DNA similarity between the $B$ chromosome and $A$ complement. Heredity. 2010;104:400-393. 